\title{
Lifetime Tests on a High Ohms/Square Metalized High Crystalline Polypropylene Film Capacitor with Application to a Marx Modulator
}

\author{
Mark A. Kemp, Craig Burkhart, Tao Tang \\ Power Conversion Department \\ SLAC National Accelerator Laboratory \\ Menlo Park, California
}

\begin{abstract}
This paper presents accelerated lifetime tests on a polypropylene film capacitor. Experimental parameters $(20 \%$ droop, $5 \mathrm{~Hz}$ repetition rate) simulate anticipated operating conditions encountered in the SLAC P2 Marx. Elevated film electric field stress is utilized as the acceleration parameter. Results indicate that, for the particular film of interest, a film stress of $\sim 290 \mathrm{~V} / \mu \mathrm{m}$ corresponds to a $10^{5}$ hour lifetime. In addition, the voltage scaling exponent for this film is 13.1.
\end{abstract}

Keywords-capacitors, pulsed power, modulators

\section{INTRODUCTION}

A second-generation prototype Marx-topology klystron modulator is under development at SLAC National Accelerator Laboratory $[1,2]$. As a part of the Marx development program, the SLAC P2 Marx builds upon experience gained from the P1 Marx [3]. One target application for this modulator is the proposed International Linear Collider (ILC). Specifications call for the modulator to produce a $1.6 \mathrm{~ms}$ pulse of $120 \mathrm{kV}$ and $140 \mathrm{~A}(+/-0.5 \%)$ at a pulse repetition frequency (p.r.f.) of 5 $\mathrm{Hz}$.

One advantage of the Marx topology is that it is composed of many identical, and ideally, redundant cells. If a particular cell becomes inoperable, it may be bypassed, the applied charge voltage increased, and the modulator operation continued. The SLAC P2 Marx has been designed with 30 out of 32 cell redundancy. In other words, two of the thirty-two cells can fail and the modulator can still produce the specified output $[2,4]$.

In addition to being redundant, cells should be easily replaceable. Maintenance staff should be able to quickly replace identified failed cells. Low mass, low volume cells are therefore necessary. In addition, some designs of the ILC require the klystron modulator to be located in a tunnel, which has minimal available floor footprint. The size and shape of the modulator, and therefore the cells, are constrained. A primary driver in the cell shape, volume, and mass is the energy storage capacitors.

Work supported by the US Department of Energy under contract DEAC02-76SF00515. E-mail: mkemp@slac.stanford.edu
Self-healing polypropylene film capacitors are attractive for use in high energy density, high power density applications. For these capacitors, there is an inverse relationship between capacitor lifetime and energy density. Scaling exponents vary based upon the characteristics of the utilized film. Therefore, it is important to properly understand the lifetime scaling relationship for a given film to specify an appropriate energy density.

This paper presents results of accelerated lifetime tests on a high ohms/square metalized high crystalline polypropylene film capacitor. The capacitors were operated under similar conditions as anticipated in the SLAC P2 Marx (20\% droop, 5 $\mathrm{Hz}$ repetition rate, $35{ }^{0} \mathrm{C}$ ambient air). Several energy densities were tested and the capacitors were run to end-of-life (reduction of capacitance by 5\%). A scaling exponent is derived along with ramifications for the SLAC P2 Marx capacitors.

\section{BACKGROUND}

\section{A. Capacitor Aging}

There have been many studies on parameters affecting aging in film capacitors [5]. Two large effects are thermal stress and the electric field in the film [6]. In the case of selfhealing capacitors, the electric field stress across the film impacts the characteristics of the "clearing" process of discharges through the film. Details on this process are outside the scope of this paper [7]. In general, high temperatures and high electric field stresses will reduce capacitor lifetime.

The temperature encountered on capacitor films are sometimes referred to as "hot spots". The hot spot temperature scales with the sum of the power dissipation due to displacement current and the power dissipation due to conduction current. This sum scales approximately as p.r.f. $* \mathrm{~V}_{\mathrm{a}}^{2}$. The hot spot temperature, $\Theta_{\text {h.s. }}$, can be, in general, expressed as

$\Theta_{\text {h.s. }}=\Theta_{\text {ambient }}+R_{\text {th, film-ambient }} \cdot\left(P_{d}+P_{c}\right)$

where $\Theta_{\text {ambient }}$ is ambient temperature, $R_{\text {th,film-ambient }}$ is the thermal resistance from the film to the ambient atmosphere, $P_{d}$ 
is power loss due to displacement current, and $\mathrm{P}_{\mathrm{c}}$ is power loss due to conduction current.

For this paper, the film lifetime scaling relationship has an assumed form of either

$$
L_{a}=\frac{L_{s} V_{s}^{\exp }}{V_{a}^{\exp }} 2^{\frac{\Theta_{r}-\Theta_{h s}}{c o e f .}}
$$

or

$L_{a}=\frac{L_{s} V_{s}^{\exp }}{V_{a}^{\exp }}$

where $\exp$ is the voltage scaling exponent, $\Theta_{\mathrm{r}}$ is a reference temperature, $\Theta_{\mathrm{hs}}$ is the hot spot temperature, coef is a temperature scaling factor, $L_{a}$ is the accelerated lifetime, $L_{s}$ is the standard lifetime, $V_{a}$ is the accelerated voltage, and $V_{s}$ is the standard voltage. These are generic forms, and have been utilized elsewhere when characterizing capacitor aging processes which depend on voltage and temperature [8-10]. In (2), the first term relates to aging due to electric field stress; the second term relates to aging due to thermal stress. In (3), only electric field stress is considered. The constants exp, coef, and $\Theta_{\mathrm{r}}$ vary based upon the film material utilized.

Ideally, one would be given $V_{s}, L_{s}$, exp, coef, and $\Theta_{\mathrm{r}}$ for a film. Then, the lifetime, $L_{a}$, for the film could be anticipated for a certain $\Theta_{\mathrm{hs}}$ and $V_{a}$. For common films and capacitor constructions, manufacturers have well-demonstrated values for the above constants [11]. For this paper, these are assumed as unknowns, and therefore experiments are conducted to determine these coefficients for the film of interest.

\section{B. Regression Analysis}

Regression analysis is utilized to analyze the experimental data and generate confidence intervals for the coefficients. Detailed later, there are only two variables in the experiment: p.r.f. and applied voltage. Therefore, scaling relationship (2) can be rewritten as a function of only p.r.f. and $\mathrm{V}_{\mathrm{a}}$,

$L_{a}\left(p . r . f ., V_{a}\right)=\frac{k_{1}}{V_{a}^{k_{2}}} 2^{\left(k_{3}-k_{4} p . r . f \cdot V_{a}^{2}\right)}$

where $\mathrm{k}_{1}-\mathrm{k}_{4}$ are constants. Equation (3) is written as

$L_{a}\left(V_{a}\right)=\frac{k_{1}}{V_{a}^{k_{2}}}$.

To perform linear regression, the scaling relationship must be put into the form

$y=c_{1} x_{1}+c_{2} x_{2}+\ldots+c_{n-1} x_{n-1}+c_{n}$

where $\mathrm{x}_{1}-\mathrm{x}_{\mathrm{n}-1}$ are the independent variables, $\mathrm{y}$ is the dependent variable, and $c_{1}-c_{n}$ are the regression coefficients. Equation (4) is transformed into this form,

$\lg \left(L_{a}\right)=\left(-k_{2}\right) \lg \left(V_{a}\right)+\left(-k_{4} \lg (2)\right) \cdot\left(p \cdot r . f \cdot V_{a}^{2}\right)$.
TABLE I. ACCELERATED LIFETIME TEST PARAMETERS

\begin{tabular}{ll}
\hline \hline $\begin{array}{l}\text { Desired "Standard" Capacitor } \\
\text { Lifetime } \\
\text { Capacitor Dielectric }\end{array}$ & $10^{5}$ hours \\
& High Ohms/Square Metalized \\
Test Capacitor Film Thickness & High Crystalline Polypropylene \\
Test p.r.f. & $5.5 \mu \mathrm{Hz}$ \\
Voltage Pulse Width & $1.6 \mathrm{~ms}$ \\
Pulse Voltage Droop & $20 \%$ \\
Test Replications & $5 \mathrm{caps} / \mathrm{test}, \sim 104 \mu \mathrm{F}$ each \\
Test Capacitor RMS Current & $<4 \mathrm{~A}_{\mathrm{rms}}$ \\
Ambient Air Temperature & $35^{\circ} \mathrm{C}$ \\
\hline \hline
\end{tabular}

TABLE II. INDIVIDUAL EXPERIMENT ELECTRIC FIELD STRESS AND PRF VALUES

\begin{tabular}{lll}
\hline \hline Experiment & $\begin{array}{c}\text { Film Electric } \\
\text { Field Stress }\end{array}$ & prf \\
\hline $\mathrm{A}$ & $393 \mathrm{~V} / \mu \mathrm{m}$ & $5 \mathrm{~Hz}$ \\
$\mathrm{~B}$ & $415 \mathrm{~V} / \mu \mathrm{m}$ & $5 \mathrm{~Hz}$ \\
$\mathrm{C}$ & $436 \mathrm{~V} / \mu \mathrm{m}$ & $5 \mathrm{~Hz}$ \\
$\mathrm{D}$ & $457 \mathrm{~V} / \mu \mathrm{m}$ & $5 \mathrm{~Hz}$ \\
$\mathrm{E}$ & $459 \mathrm{~V} / \mu \mathrm{m}$ & $4.1 \mathrm{~Hz}$ \\
\hline \hline
\end{tabular}

Similarly, equation (5) transforms to

$\lg \left(L_{a}\right)=\left(-k_{2}\right) \lg \left(V_{a}\right)+\lg \left(k_{1}\right)$.

Of primary interest is the constant $\mathrm{k}_{2}$, which corresponds to the voltage scaling exponent, exp.

\section{EXPERIMENTAL SETUP}

A film which was utilized in the main storage capacitors in the P1 Marx was selected as the baseline film to utilize in the SLAC P2 Marx storage capacitors. To adequately determine the appropriate energy density to specify for the capacitors, an accelerated lifetime test was setup.

Five capacitors with the same film composition as the baseline SLAC P2 Marx capacitor were connected in parallel. They were charged to a given setpoint, discharged into a resistive load for $1.6 \mathrm{~ms}$, recharged to the voltage setpoint, and discharged again. For the majority of tests, the pulse repetition frequency was $5 \mathrm{~Hz}$. The resistive load was set such that the capacitor voltage droop was $20 \%$ during the pulse. The ambient air temperature was controlled to $35 \pm 1{ }^{\circ} \mathrm{C}$. The recharge time, $\sim 30 \mathrm{~ms}$, was dictated by the available power supply. The tests were allowed to run 24/7. Periodically, the tests were interrupted and the capacitors were allowed to equilibrate with the ambient laboratory temperature for 1 day. After, the capacitance of the individual capacitors was measured with a precision LCR meter. Tests were run until one of the capacitors reduced in capacitance by $5 \%$, the criteria for end of life.

\section{RESULTS AND ANALYSIS}

Five tests were conducted with various electric field stresses on the films. These values are summarized in Table II. The measured capacitance values for each of the capacitors during the test are shown in Fig. 1. Each of the capacitors are assumed to be identical at the onset of the experiment. For capacitors which did not reach end of life, an estimate is made for the anticipated time of end of life. A second-order 


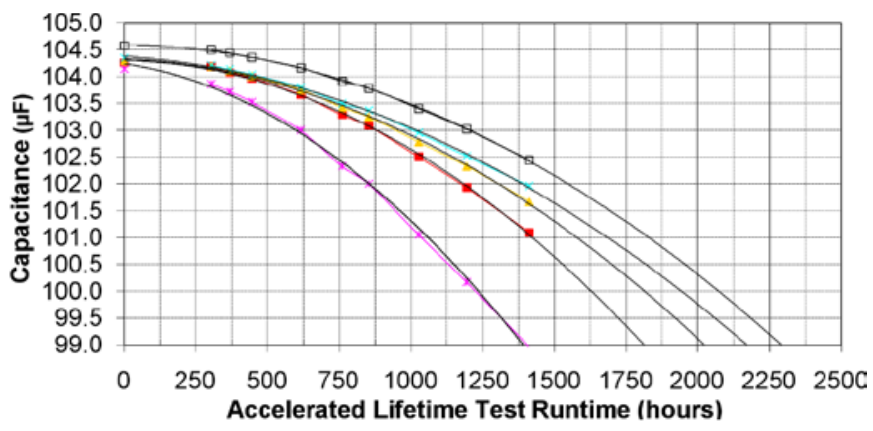

(a)

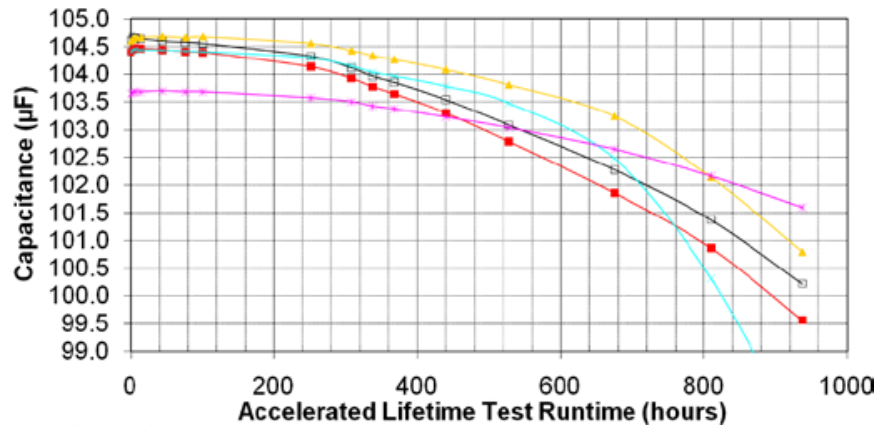

(b)

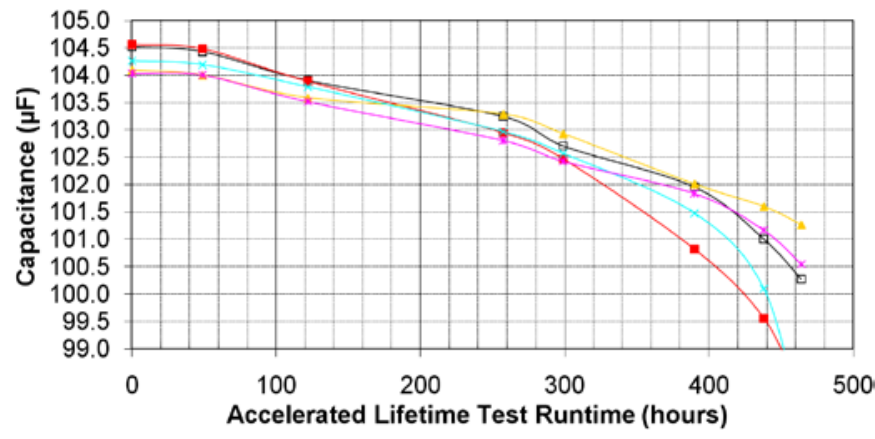

(c)

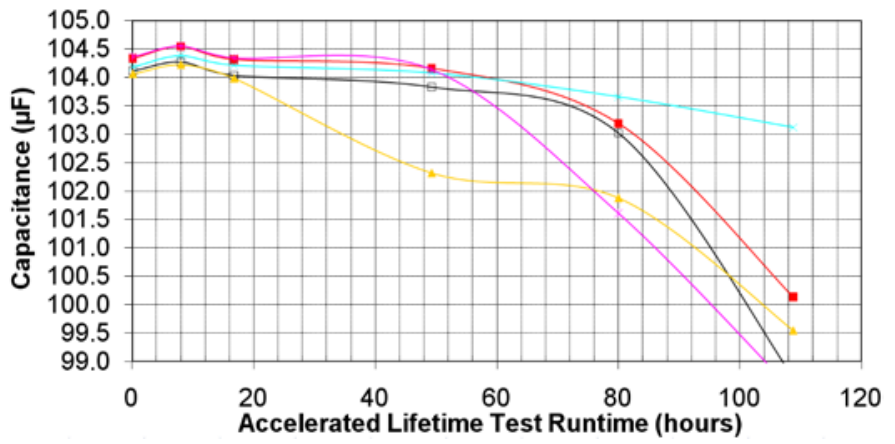

(d)

Figure 1. Capacitance measured across an individual capacitor during the accelerated lifetime tests. Five capacitors were tested for each film stress of interest. Average film stress is (a) $393 \mathrm{~V} / \mu \mathrm{m}$, (b) $415 \mathrm{~V} / \mu \mathrm{m}$, (c) $436 \mathrm{~V} / \mu \mathrm{m}$, and (d) $457 \mathrm{~V} / \mu \mathrm{m}$. Shown in (a) are second-order polynomial fits to the data.

polynomial was fit to the data; example trend lines are shown in Fig. 1a. When the trend line value is $99 \mu \mathrm{F}$, the

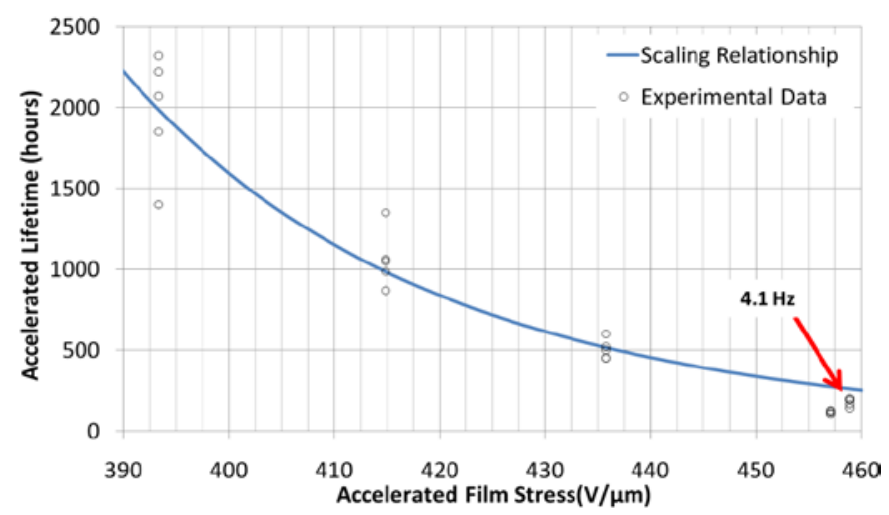

Figure 2. Times when capacitors reached end of life for various film stresses. All are with an applied voltage p.r.f. of $5 \mathrm{~Hz}$, except the points where noted by an arrow, which are for a p.r.f. of $4.1 \mathrm{~Hz}$. The solid line is the assumed scaling relationship $\left(E_{s}=292 \mathrm{~V} / \mu \mathrm{m}\right.$, exp $\left.=13.1\right)$. Note that data at a film stress of $\sim 455 \mathrm{~V} / \mu \mathrm{m}$, experiments $\mathrm{D}$ and $\mathrm{E}$, are excluded from the calculation to determine the scaling relationship. It is assumed other factors contributed to the end of life in those cases.

corresponding end of life time is assigned to the capacitor. Shown in Fig. 2 is a summary of these end-of-life values.

There are several qualitative observations of the data. As the applied electric field stress on a film is increased, the end of life condition is reached sooner. In addition, for experiments A and $\mathrm{B}$, the degradation in capacitance is a smoother path than in experiments $\mathrm{C}$ and $\mathrm{D}$. In fact, for experiment $\mathrm{A}$, the second order polynomial is almost an exact fit to the capacitance decrease. Finally, as shown in the right half of Fig. 2, the higher field-stress experiment $\mathrm{E}$ reached end of life later than experiment D. This is only explained by the lower p.r.f., and therefore lower thermal stress, of experiment E compared to D.

In self-healing capacitors, the ability of a discharge to gracefully "clear" is partially determined by the amount of energy in the discharge. Larger energy discharges will have erratic clearing characteristics and might lead to premature capacitor failure [6]. This might be an explanation for the higher field stress experiments exhibiting less-smooth paths to end of life. An additional possibility is that other high-voltage effects such as corona-initiated degradation might start playing a role in reducing film lifetime.

A regression analysis was performed on the data from experiments A-E. The data were transformed into the model

TABLE III. REGRESSION COEFFICIENTS FOR A MULTIPLE LINEAR REGRESSION WITH A MODEL GIVEN BY (7) AND DATA FROM EXPERIMENTS A-E

\begin{tabular}{llll}
\hline \hline $\begin{array}{c}\text { Regression } \\
\text { Coefficient }\end{array}$ & p-value & \multicolumn{1}{c}{$\begin{array}{c}\text { Coefficient } \\
\text { Value }\end{array}$} & $\begin{array}{c}\text { 95\% Confidence } \\
\text { Interval }\end{array}$ \\
\hline $\lg \left(\mathrm{k}_{1}\right)+\mathrm{k}_{3} \lg (2)$ & 0.000 & 55.49 & $46.5-64.4$ \\
$-\mathrm{k}_{2}$ & 0.000 & -15.91 & $-13.1--18.8$ \\
$-\mathrm{k}_{4} \lg (2)$ & 0.172 & $-2.8 * 10^{-8}$ & $-6.8^{*} 10^{-8}-1.3 * 10^{-8}$ \\
\hline \hline
\end{tabular}

TABLE IV. REGRESSION COEFFICIENTS FOR A LINEAR REGRESSION WITH A MODEL GIVEN BY (8) AND DATA FROM EXPERIMENTS A-C

\begin{tabular}{llll}
\hline \hline $\begin{array}{c}\text { Regression } \\
\text { Coefficient }\end{array}$ & p-value & $\begin{array}{c}\text { Coefficient } \\
\text { Value }\end{array}$ & $\begin{array}{c}\mathbf{9 5 \%} \text { Confidence } \\
\text { Interval }\end{array}$ \\
\hline $\lg \left(\mathrm{k}_{1}\right)$ & 0.000 & 46.0 & $38.4-53.6$ \\
$-\mathrm{k}_{2}$ & 0.000 & -13.1 & $-10.8--15.5$ \\
\hline \hline
\end{tabular}


TABLE V.CALCULATED STANDARD ELECTRIC FIELD STRESS FOR $10^{5}$ HOURS LIFETIME.

\begin{tabular}{ll}
\hline \hline $\begin{array}{c}\text { Voltage Scaling } \\
\text { Exponent }\end{array}$ & $\begin{array}{c}\text { Calculated Standard } \\
\text { Electric Field }\end{array}$ \\
\hline 10.8 & $272 \mathrm{~V} / \mu \mathrm{m}$ \\
13.1 & $292 \mathrm{~V} / \mu \mathrm{m}$ \\
15.5 & $306 \mathrm{~V} / \mu \mathrm{m}$ \\
\hline \hline
\end{tabular}

given by (7). Results from the analysis are summarized in Table III. Only two of the three coefficients were statistically significant at the $\alpha=0.05$ level. The non-significant coefficient $k_{4}$ is associated with thermal effects. Certainly thermal effects play a role in determining capacitor lifetime. However, the experiments presented in this study did not statistically prove them.

Because a coefficient in the model was not significant, the regression model was changed to (8). In this model, there is not a term corresponding to thermal effects. This model may be more appropriate for the capacitor operating parameters in the SLAC P2 Marx. The intended operation is at a relatively low RMS current (lower than in the accelerated lifetime tests) than is typical for polypropylene film capacitors. Electric field effects likely dominate film aging. However, because of the non-smooth capacitance degradation in experiments D and E and because it was demonstrated that thermal effects are partially contributing to determining the end of life, these data are censored from the linear regression summarized in Table IV.

The coefficient $\mathrm{k}_{2}$ represents the voltage scaling exponent, exp, for this film. For similar polypropylene, self-healing film capacitors, voltage scaling exponents in the range of 13.5-16.4 [7] or 18.7-20.3 [11] are reported. The target application for the capacitors utilized in the P2 Marx calls for a lifetime of $10^{5}$ hours. To determine the corresponding "standard" field stress on the film, a least squares fit is performed for each of the voltage scaling exponents in Table IV to the experimental data from experiments A-C. Results are summarized in Table V.

\section{SUMMARY}

In the SLAC P2 Marx, it is important to utilize energy storage capacitors with an appropriate energy density. There have been many studies examining the degradation processes associated with film capacitors. However, the precise nature of degradation varies from film to film. An accelerated lifetime test was conducted on the film capacitors chosen as a baseline for the Marx. The goal was to specify the field stress to be utilized in the capacitor design.

The experiments did not conclusively prove that thermal effects were significant in degradation of the capacitors in the operating range of interest. The $95 \%$ confidence interval for the voltage scaling exponent was found to be 10.8-15.5. Therefore, for $10^{5}$ hours lifetime, the SLAC P2 Marx capacitors will utilize a field stress of 272-306 V/ $\mathrm{m}$. This corresponds to a capacitor energy density of $\sim 0.5 \mathrm{~J} / \mathrm{cm}^{3}$.

\section{REFERENCES}

[1] M.A. Kemp, et al., "Status update on the second-generation ILC Marx modulator prototype," presented this conference.

[2] K. Macken, et al., "Towards a PEBB-based design approach for a Marxtopology ILC klystron modulator," presented at the 2009 Patricle Accelerator Conf., Vancouver, Canada, May 2009.

[3] C. Burkhart, et al., "P1-Marx modulator for the ILC," presented this conference.

[4] A. Benwell, et al., "A prognostic method for scheduling maintenance on the P2-Marx modulator," presented this conference.

[5] V.A. Agarwal, "Aging of Multistressed Polymeric Insulators," IEEE Trans. Electr. Insul., vol. 24, pp. 741-764, 1989.

[6] C.W. Reed and S.W. Cichanowski, "The Fundamentals of Aging in hv Polymer-film Capacitors", IEEE Trans. Dielectr. Elect. Insul., vol. 1, pp. 904-9252, 1994.

[7] W.J. Sarjeant, et al., "Energy Storage Capacitors Aging and Diagnostic Approaches for Life Validation," IEEE Trans. Mag., vol. 33, pp. 501506, 1997.

[8] B. R. Hayworth, "The behavior of polyester film energy storage capacitors," IEEE Trans. Electr. Insul., May 1968.

[9] G. P. Boicourt, "Capacitor development for Scyllac," in Proc. Sym. Eng. Problems Fusion Res., Jan. 1970, pp. C.I.1.1-6.

[10] D.L. Smith, et al., "ZR Marx capacitor vendor evaluation and lifetime test results," IEEE Trans. Plasma Sci., vol. 33, no. 4, Aug. 2005, pp. 1273.

[11] AVX, "AVX medium power film capacitors for power applications," datasheet, version 10.2. 